\title{
The Detection Distance of Colored Target using Various Automotive Headlamps
}

\author{
Jung Yong Kim ${ }^{1,2}$, Ho Sang Lee ${ }^{1}$, Seung Nam Min ${ }^{1}$, Min Ho Lee ${ }^{1}$ \\ ${ }^{1}$ Department of Industrial and Management Engineering, Hanyang University, Ansan, Korea 426-791 \\ ${ }^{2}$ Institute of Aging Society, Hanyang University, Seoul, Korea 133-791
}

\begin{abstract}
Objective: As headlamp technology advances, newly developed various headlamps were introduced in the market. The objective of this study is to quantitatively analyze the detection distance of the recently developed LED headlamps and existing headlamps, complying with specific technical standard. Background: The detection distance of headlamps is very important to prevent automobile accident at night time. The studies of detection distance of LED, Halogen and HID headlamp have been conducted, but no study has shown the detection distance of pedestrian target with various colors (Black, White, Blue). Method: The experiment of detection distance was conducted with 30 people, which divide into 2 groups as 15 men and 15 women. Automatic transferable target on the rail was manufactured in order to reduce the error of study's result, and ANOVA also conducted to analyze the main effect with sign color, sex and headlamp classified by detection distance. In addition, the luminance by average detection distance was measured as well. Results: The detection distance of headlamps was HID > LED > Halogen. The luminance measure of LED headlamp was lower than HID and Halogen headlamps. Conclusion: The headlamp performs a very significant role for safety at night time but it needs to be improved through assessment of visual characteristics. Also, it needs to be suggested the need of test method for dynamic detection distance concerning technical development is suggested.
\end{abstract}

Keywords: Halogen, HID(High Intensity Discharge), LED, Headlamps, Detection distance, Luminance measurement, Target, Color temperature

\section{Introduction}

전조등은 모든 자동차에 필수적으로 부착된다. 전조등 의 가장 중요한 기능은 도로 및 주변환경에 빛을 조사하 여 운전자에게 충분한 시야정보를 제공하는 것이며, 대향 차 운전자에게 눈부심을 유발하지 않아야 한다고 하였다 (Wördenweber et al., 2006). Hung et al.(2010)은 최근 개발되고 있는 전조등은 광원 및 제작기술의 발전에 따라 할 로겐, 가스방전식(HID), $\mathrm{LED}, \mathrm{DMD}$ (Digital Micromirror
Device) 전조등 순으로 발전되고 있다고 하였다. Völker et al. (2005)은 전조등 기술발전에 따라 증가된 광출력과 높은 색온도가 제공되고 있지만, 전자제어기술의 발달로 인해 운 전자의 눈부심은 감소시키고, 편안함은 증가한다고 보고하 였다.

최근에는 자동차 전방상황을 감지할 수 있는 레이더나 센 서기술이 전조등 제어기술과 결합되어 야간 식별거리를 증가 시킬 수 있는 $\mathrm{ADB}$ (Adaptive Driving Beam) 전조등도 소 개되고 있다(Wördenweber et al., 2006). 식별거리에 대한 기존 최근 연구를 보면, 할로겐, HID (Parabolic, Projector

Corresponding Author: Ho Sang Lee. Department of Industrial and Management Engineering, Hanyang University, Ansan, Korea 426-791. 
type) 전조등에 대한 보행자 식별실험 결과 Projector type $\mathrm{HID}$ 전조등이 가장 높았다(Chen et al., 2008). 또한 $20 \times$ $20 \mathrm{~cm}$ 인 회색 표지판을 이용하여 할로겐, $\mathrm{HID}, \mathrm{LED}$ 전조등 에 대한 식별거리를 분석한 결과에서도 HID 전조등이 LED, 할로겐 전조등보다 우수한 것으로 분석되었다(Schiller et al., 2008). 그리고 Wood et al.(2003)은 보행자의 색상을 검은 색 (2\% 반사율), 백색(68\% 반사율)로 구분하여 식별률을 분석한 결과, 검은색의 평균 식별률은 $33.75 \%$, 백색의 평균 식별률은 $83.75 \%$ 로 반사율이 높은 백색에서 식별률이 높았 다. Blanco et al. (2005)은 검은색, 청색, 보행자로 구분하여 식별률을 분석한 결과 검은색의 평균 식별수준은 4 , 청색의 식별수준은 7.5 로 청색의 식별수준이 높았다. 이와 같이 전 조등의 식별거리는 자동차의 위치, 표지판의 휘도와 반사율, 형태, 크기, 자동차 종류와 전조등 형태 그리고 도로 특성 및 기후와 같은 다양한 조건에 따라 영향을 받는다고 보고하고 있다(Aleksanteri et al., 2008). 한편 Bullough(2010)는 야간운전 시 전조등의 역할이 매우 높기 때문에 운전자의 시각적인 특성과 기술발전에 따른 평가방법의 개선이 필요 하다고 하였다. 그래서 본 연구에서는 최근 국내에서 상용화 된 $\mathrm{LED}$ 전조등과 기존 $\mathrm{HID}$, 할로겐 전조등에 대한 보행자 색상별 식별거리를 자동으로 이동되는 레일을 제작하여 분 석하고자 한다.

\section{Methodology}

\subsection{Participants}

식별거리 실험은 연령대별 사고건수 비율이 가장 높은 30 40대 남성 및 여성으로 하였다(보험개발원, 2008). 실 험참가자는 남녀 각 15 명씩 30 명을 대상으로 진행하였다 (Table 1). 실험참가자의 최소시력은 $0.5 \mathrm{D}$ 이상이었고, 운 전경력은 최소 3 년 이상이었다.

Table 1. Demographic information for participants

\begin{tabular}{c|c|c}
\hline & Male & Female \\
\hline Number & 15 & 15 \\
\hline Age (year) & $39.1 \pm 12.0$ & $44.5 \pm 5.8$ \\
\hline Driving experience(year) & $11.2 \pm 6.3$ & $10.1 \pm 6.3$ \\
\hline Average left eyesight(D) & $1.1 \pm 0.3$ & $1.0 \pm 0.2$ \\
\hline Average right eyesight(D) & $1.1 \pm 0.3$ & $1.0 \pm 0.2$ \\
\hline Minimum left eyesight(D) & 0.5 & 0.8 \\
\hline Minimum right eyesight(D) & 0.7 & 0.8 \\
\hline
\end{tabular}

\subsection{Hypothesis}

$\mathrm{LED}$ 전조등과 기존 $\mathrm{HID}$, 할로겐 전조등에 대한 식별거리 는 보행자 역할의 표지판 색상과 운전자의 성별에 따라 달라 질 거라는 가정하에 귀무가설을 설정하였다.

- 귀무가설 (HO): 운전자의 성별, 보행자 역할의 표지판 및 전조등 종류에 따라 식별거리의 차이가 없다.

\subsection{Apparatus}

실험자동차는 에쿠스(LED 전조등) 1 대, 제네시스 2 대(할 로겐, HID 전조등) 총 3 대의 차를 선정하였다. 실험자동차는 전조등 설치높이에 따라 식별거리의 차이가 발생할 수 있기 때문에 최근 개발된 LED 전조등의 설치높이와 유사한 높이 의 제네시스를 선정하였다(Table 2a). 그리고 전조등별 파 장 및 색온도는 Minolta CS1000을 이용하여 3회씩 측정 하여 비교하였다(Table 2b).

Table 2. Characteristics of headlamp sample test

\begin{tabular}{l|c|c|c}
\hline Light source & Halogen & HID & LED \\
\hline Automobile & & \\
Headlamp & 710 & 710 & 750 \\
\hline $\begin{array}{c}\text { Installation } \\
\text { Height(mm) }\end{array}$ & 710 & \\
\hline
\end{tabular}

(a) Automobile and Headlamp

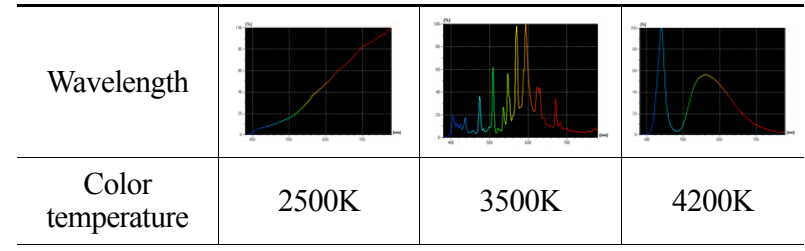

(b) Wavelengths and Color temperature

Figure 1 과 같이 식별거리 실험은 보행자를 대신하는 3 가 지 색상(백색, 청색, 검은색)의 표지판을 제작하여 수행하였 다(Blanco, 2005). 표지판의 치수는 Size Korea 제5차 한 국인 인체치수조사사업 보고서의 남자 성인 평균 키를 기초 로 제작하였고, Minolta 2600D를 이용하여 색상별 표지판의 반사율 $(\%)$ 을 10 회씩 측정하여 비교하였다(Table 3$)$. 


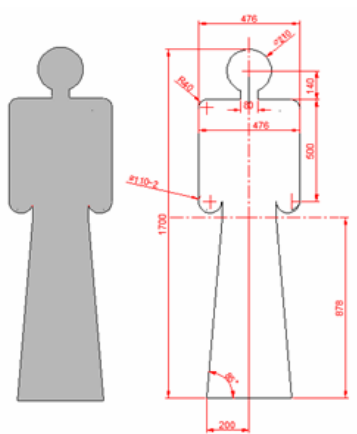

Figure 1. Target using experiment

Table 3. Target reflectance by color

\begin{tabular}{c|c|c|c}
\hline Color & White & Blue & Black \\
\hline Reflectance $(\%)$ & $75.7 \pm 0.68$ & $9.3 \pm 0.22$ & $2.7 \pm 0.22$ \\
\hline
\end{tabular}

\subsection{Procedure}

전조등별 식별거리 실험을 위해 표지판이 자동으로 이동 되는 $100 \mathrm{~m}$ 레일을 제작하였다(Figure 2). 실험을 실시하기 전, 참가자들에게 연구 목적과 실험순서를 설명하였고, 식별 거리 실험에 익숙해지도록 실험장소에서 제어기 작동방법과 표지판 식별방법에 대해 상세히 설명하였다. 실험참가자는 정위치된 자동차 운전석에 착석한 후 제어기를 이용하여 $150 \mathrm{~m}$ 거리에서부터 표지판을 이동시키면서 표지판이 식별 되는 시점에서 컨트롤러 조작을 멈추도록 하였다. 그리고 제어기 표시장치에 자동으로 표시되는 거리를 식별거리로 확인하고, 설문지에 기재하는 방법으로 진행하였다. 이러한 순서로 자동차와 표지판을 교체하면서 진행하였다(Figure 3). 또한 전조등별 표지판의 휘도를 측정하기 위해 $\mathrm{LMK}$ 사 의 EOS 450D 카메라를 이용하여 촬영하였고, Labsoft 프로 그램을 이용하여 분석하였다. 실험은 자동차성능연구소 주행 시험장내 종합시험로에서 실시하였다.

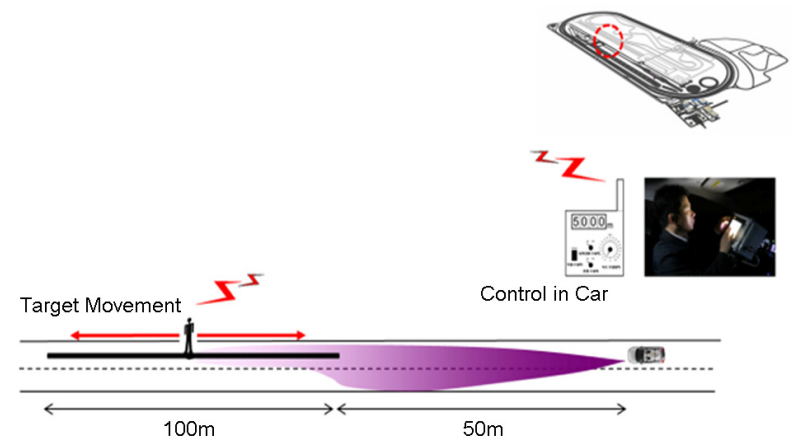

Figure 2. Experiment procedure

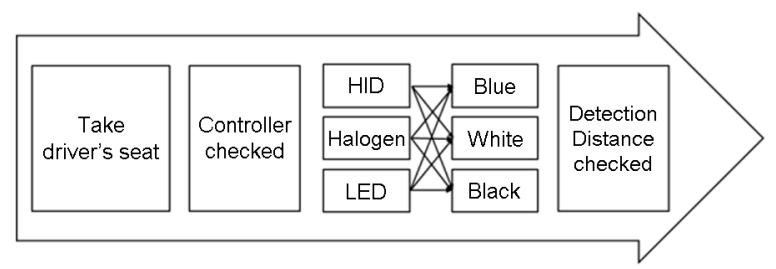

Figure 3. Experiment method

\subsection{Data analysis}

본 실험분석에서는 각 종속변수별 독립변수(표지판 색상, 성별, 전조등 종류)의 영향을 보기 위해 통계패키지 SPSS 15.0 을 이용하여 분산분석(ANOVA)을 실시하였다.

\section{Results}

\subsection{Detection distance}

Table 4는 실험참가자로부터 측정된 식별거리를 종속변수 로 하고, 성별(Sex), 보행자 역할의 표지판 색상(Color), 전 조등의 종류(Light source)를 독립변수로 분산분석을 실시 한 결과이다. 운전자의 성별에 따라서는 차이가 없는 것으로 나타났으나, 표지판의 색상과 전조등의 종류에 따라 유의수 준 0.01에서 차이가 있는 것으로 나타났다. 또한 유의수준 0.01에서 색상과 성별에 따른 교호작용과 색상과 전조등의 종류에 따른 교호작용이 나타났다.

Table 4. ANOVA for detection distance

\begin{tabular}{l|r|c|r|r}
\hline Source & \multicolumn{1}{|c|}{ SS } & df & \multicolumn{1}{c|}{ MS } & \multicolumn{1}{c}{ F } \\
\hline Sex & 71.66 & 1 & 71.66 & $0.27^{\mathrm{a}}$ \\
\hline Color & 106785.92 & 2 & 53392.96 & $582.50^{* * *}$ \\
\hline Color * Sex & 1189.69 & 2 & 594.85 & $6.49^{* * *}$ \\
\hline Light source & 17163.74 & 2 & 8581.87 & $267.04^{* * *}$ \\
\hline Light source * Sex & 142.94 & 2 & 71.47 & $2.22^{\mathrm{a}}$ \\
\hline Color * Light source & 4155.39 & 4 & 1038.85 & $31.98^{* * *}$ \\
\hline $\begin{array}{l}\text { Color * Light source } \\
\text { * Sex }\end{array}$ & 877.22 & 4 & 219.30 & $0.75^{\mathrm{a}}$ \\
\hline
\end{tabular}

${ }_{* * *}^{\text {a. }}$ Non-significant

$: p<0.01$

유의수준 0.01에서, 표지판의 색상(Color)에 따라 각 성 별 $\mathrm{Sex}$ )에 관한 식별거리의 차이가 있는 것으로 나타났다 (Table 4). 교호작용이 나타난 표지판 색상과 성별에 대해 
서 1 수준으로 나누어서 비교해 보았다. 그 결과, 표지판 색 상에서는 백색, 청색, 검정색 순서로 식별거리가 길었으며, 성별에 따른 식별거리 차이는 없었다(Table 5).

Table 5. Comparison of detection distance by sex and color

\begin{tabular}{c|c|c}
\hline Male White $(107.83 \mathrm{~m})$ & $>$ & Male Blue $(84.93 \mathrm{~m})$ \\
\hline Male White $(107.83 \mathrm{~m})$ & $>$ & Male Black $(64.07 \mathrm{~m})$ \\
\hline Male White $(107.83 \mathrm{~m})$ & $=$ & Female White $(114.68 \mathrm{~m})$ \\
\hline Male White $(107.83 \mathrm{~m})$ & $>$ & Female Blue $(84.07 \mathrm{~m})$ \\
\hline Male White $(107.83 \mathrm{~m})$ & $>$ & Female Black $(61.18 \mathrm{~m})$ \\
\hline Male Blue $(84.9 \mathrm{~m} 3)$ & $>$ & Male Black $(64.07 \mathrm{~m})$ \\
\hline Male Blue $(84.93 \mathrm{~m})$ & $<$ & Female White $(114.68 \mathrm{~m})$ \\
\hline Male Blue $(84.93 \mathrm{~m})$ & $=$ & Female Blue $(84.07 \mathrm{~m})$ \\
\hline Male Blue $(84.93 \mathrm{~m})$ & $>$ & Female Black $(61.18 \mathrm{~m})$ \\
\hline Male Black $(64.07 \mathrm{~m})$ & $<$ & Female White $(114.68 \mathrm{~m})$ \\
\hline Male Black $(64.07 \mathrm{~m})$ & $<$ & Female Blue $(84.07 \mathrm{~m})$ \\
\hline Male Black $(64.07 \mathrm{~m})$ & $=$ & Female Black $(61.18 \mathrm{~m})$ \\
\hline Female White $(114.68 \mathrm{~m})$ & $>$ & Female Blue $(84.07 \mathrm{~m})$ \\
\hline Female White $(114.68 \mathrm{~m})$ & $>$ & Female Black $(61.18 \mathrm{~m})$ \\
\hline Female Blue $(84.07 \mathrm{~m})$ & $>$ & Female Black $(61.18 \mathrm{~m})$ \\
\hline
\end{tabular}

$>,<: p<0.0033,=:$ Non-significant

유의수준 0.01에서, 표지판의 색상(Color) 과 전조등의 종 류(Light Source)에 대해 교호작용이 나타났다(Table 4). 교호작용이 나타난 색상과 전조등의 종류에 대해 1 수준으로 나누어서 비교해 보았다. 그 결과, $\mathrm{HID}$, 할로겐, $\mathrm{LED}$ 전조등 순으로 식별거리가 길었고, 색상에서는 백색, 청색, 검정색 순서로 식별거리가 길게 나타났다. 단, 색상에 따라서 백색 할로겐 전조등과 청색 $\mathrm{HID}$ 전조등, 백색 $\mathrm{LED}$ 전조등, 청색 $\mathrm{HID}$ 전조등, 검정 $\mathrm{HID}$ 전조등과 검정 $\mathrm{LED}$ 전조등에서 유 의한 차이가 나타나지 않았다(Table 6).

Table 6. Comparison of detection distance by color and light source

\begin{tabular}{c|c|c}
\hline White Halogen $(102.55 \mathrm{~m})$ & $<$ & White HID $(125.79 \mathrm{~m})$ \\
\hline White Halogen $(102.55 \mathrm{~m})$ & $=$ & White LED $(105.42 \mathrm{~m})$ \\
\hline White Halogen $(102.55 \mathrm{~m})$ & $>$ & Blue Halogen $(72.88 \mathrm{~m})$ \\
\hline White Halogen $(102.55 \mathrm{~m})$ & $=$ & Blue HID $(98.54 \mathrm{~m})$ \\
\hline White Halogen $(102.55 \mathrm{~m})$ & $>$ & Blue LED $(82.08 \mathrm{~m})$ \\
\hline White Halogen $(102.55 \mathrm{~m})$ & $>$ & Black Halogen $(56.78 \mathrm{~m})$ \\
\hline White Halogen $(102.55 \mathrm{~m})$ & $>$ & Black HID $(65.69 \mathrm{~m})$ \\
\hline White Halogen $(102.55 \mathrm{~m})$ & $>$ & Black LED $(65.40 \mathrm{~m})$ \\
\hline
\end{tabular}

Table 6. Comparison of detection distance by color and light source (Continued)

\begin{tabular}{|c|c|c|}
\hline White HID(125.79m) & $>$ & White LED(105.42m) \\
\hline White HID(125.79m) & $>$ & Blue Halogen $(72.88 \mathrm{~m})$ \\
\hline White HID(125.79m) & $>$ & Blue HID(98.54m) \\
\hline White HID(125.79m) & $>$ & Blue LED(82.08m) \\
\hline White HID(125.79m) & $>$ & Black Halogen $(56.78 \mathrm{~m})$ \\
\hline White HID(125.79m) & $>$ & Black HID(65.69m) \\
\hline White HID(125.79m) & $>$ & Black LED(65.40m) \\
\hline White LED(105.42m) & $>$ & Blue Halogen $(72.88 \mathrm{~m})$ \\
\hline White LED(105.42m) & $=$ & Blue HID(98.54m) \\
\hline White LED $(105.42 \mathrm{~m})$ & $>$ & Blue LED(82.08m) \\
\hline White LED(105.42m) & $>$ & Black Halogen $(56.78 \mathrm{~m})$ \\
\hline White LED(105.42m) & $>$ & Black HID(65.69m) \\
\hline White LED(105.42m) & $>$ & Black LED(65.40m) \\
\hline Blue Halogen(72.88m) & $<$ & Blue HID(98.54m) \\
\hline Blue Halogen(72.88m) & $<$ & Blue LED(82.08m) \\
\hline Blue Halogen(72.88m) & $>$ & Black Halogen $(56.78 \mathrm{~m})$ \\
\hline Blue Halogen(72.88m) & $>$ & Black HID(65.69m) \\
\hline Blue Halogen(72.88m) & $>$ & Black LED(65.40m) \\
\hline Blue HID(98.54m) & $>$ & Blue LED $(82.08 \mathrm{~m})$ \\
\hline Blue HID(98.54m) & $>$ & Black Halogen $(56.78 \mathrm{~m})$ \\
\hline Blue HID(98.54m) & $>$ & Black HID(65.69m) \\
\hline Blue HID(98.54m) & $>$ & Black LED $(65.40 \mathrm{~m})$ \\
\hline Blue LED(82.08m) & $>$ & Black Halogen $(56.78 \mathrm{~m})$ \\
\hline Blue LED $(82.08 \mathrm{~m})$ & $>$ & Black HID(65.69m) \\
\hline Blue LED(82.08m) & $>$ & Black LED $(65.40 \mathrm{~m})$ \\
\hline Black Halogen $(56.78 \mathrm{~m})$ & $<$ & Black HID(65.69m) \\
\hline Black Halogen $(56.78 \mathrm{~m})$ & $<$ & Black LED $(65.40 \mathrm{~m})$ \\
\hline Black HID(65.69m) & $=$ & Black LED(65.40m) \\
\hline
\end{tabular}

$>,<: p<0.0014,=:$ Non-significant

\subsection{Luminance measurement}

휘도카메라를 이용하여 전조등에 대한 색상별 표지판의 휘도를 측정하였다(Figure 4). 그리고 전조등에 대한 평균 식별거리를 측정된 휘도값으로 비교해 보았다(Table 7). 전 조등별 휘도 측정결과, 할로겐 전조등은 0.0825 0.1142 $\mathrm{cd} / \mathrm{m}^{2}$, HID 전조등은 $0.071 \sim 0.11 \mathrm{~cd} / \mathrm{m}^{2}$, LED 전조등은 $0.0384 \sim 0.0492 \mathrm{~cd} / \mathrm{m}^{2}$ 범위 내에서 보행자를 대신하여 실 험에 사용된 표지판을 식별할 수 있는 것으로 분석되었다. 
Table 7. Measured luminance

\begin{tabular}{c|c|c|c|c|c|c|c|c|c}
\hline \multirow{2}{*}{$\begin{array}{c}\text { Luminance } \\
\left(\mathrm{cd} / \mathrm{m}^{2}\right)\end{array}$} & \multicolumn{3}{|c|}{ White } & \multicolumn{3}{c|}{ Blue } & \multicolumn{3}{c}{ Black } \\
\cline { 2 - 26 } & Halo & HID & LED & Halo & HID & LED & Halo & HID & LED \\
\hline Mean & 0.0825 & 0.0726 & 0.0384 & 0.0908 & 0.071 & 0.0492 & 0.1142 & 0.11 & 0.041 \\
\hline
\end{tabular}

※ Halo: Halogen

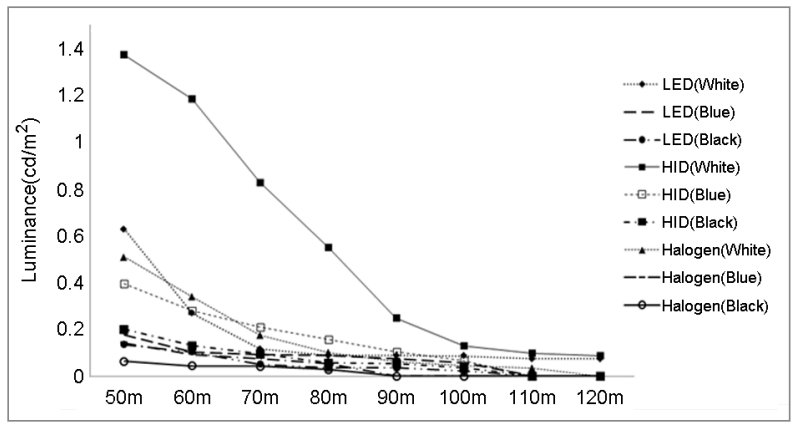

Figure 4. Luminance measurement

\section{Discussion}

본 연구는 기존에 사용되고 있는 할로겐, HID 전조등과 최 근 적용된 $\mathrm{LED}$ 전조등의 대한 식별거리와 식별거리에 따른 색상별 표지판의 휘도를 분석하였다. 전조등에서 조사되는 빛에 의한 식별거리 및 휘도를 분석하기 위해 색상별로 한국 인 인체모형 표지판을 자동으로 이동시킬 수 있는 레일을 제작하여 실험하였다. 기존 연구에서는 $5 \mathrm{~m}, 10 \mathrm{~m}$ 거리별로 각각 설치된 고정형 표지판을 사용하여 식별거리를 측정하 였다(Chen et al., 2008). 그러나 고정으로 설치된 표지판 은 실험방법상 오차가 발생할 수 있다. 실험의 오차를 줄이 고, 실험방법을 개선하기 위하여 표지판을 자동으로 이동시 킬 수 있는 레일을 제작하였고, 한국인 인체모형 크기로 표 지판을 제작하여 적용하였다. 이러한 실험방법은 전조등에 의한 식별거리뿐만 아니라 표지판의 시각적 특성 (크기, 대비 (contrast), 위치 등) 을 다양하게 분석하는데 확대 적용할 수 있을 것으로 판단된다.

실험결과 $\mathrm{LED}$ 전조등은 저전력, 고효율과 같은 장점으로 인해 식별거리가 기존 전조등보다 길 것으로 예측하였다. 그 러나 표지판의 색상별 식별거리 분석결과, $\mathrm{LED}$ 전조등은 기 존 $\mathrm{HID}$ 전조등보다 $12.37 \mathrm{~m}$ 가 더 짧았으며 할로겐 전조등 보다는 $6.9 \mathrm{~m}$ 더 길었다. 이러한 결과는 고정형 표지판을 이 용한 기존 연구결과와 유사하였다(Schiller et al., 2008).

기존(할로겐, HID) 전조등은 열에 많은 영향을 받지 않았
으나, LED 전조등은 열에 매우 민감하게 반응한다(Tetsuaki Inaba et al., 2008). 자동차 엔진룸과 전조등 내에 열이 발 생되어 외부로 방열이 되지 않으면 LED에서 조사되는 빛이 감소되어 식별거리가 감소될 수 있다. 본 실험은 자동차가 정지된 상태에서 전조등의 식별거리와 휘도를 측정한 것으 로 자동차가 주행 시에는 엔진룸과 전조등 내 자연대류가 발생하여 $\mathrm{LED}$ 의 열이 감소되기 때문에 식별거리가 증가될 수 있다. 자동차 조건(정지, 주행)에 따른 식별거리에 대한 추가적인 연구가 필요한 부분이라 할 수 있다.

표지판 색상별 식별거리 비교결과, 백색이 가장 길었고, 청색 그리고 검은색 순서이었다. 색상별 식별거리의 차이는 표지판의 반사율에 따라 차이가 발생하고 있다고 판단할 수 있었다(Table 3).

표지판 색상별 휘도 측정결과, $0.0384 \sim 0.1142 \mathrm{~cd} / \mathrm{m}^{2}$ 범 위에서 보행자 역할을 대신한 인체모형 표지판을 식별하는 것으로 분석되었다. 그러나 $\mathrm{LED}$ 전조등은 기존 할로겐 전조 등, $\mathrm{HID}$ 전조등과 비교하여 낮은 휘도에서 표지판을 식별하 였다. $\mathrm{LED}$ 전조등에서 조사되는 빛은 기존 전조등에서 조사 되는 빛의 색온도 보다 높았다(Table 2). 색온도가 높아짐 에 따라 자연광에 가까운 빛이 조사되는 LED 전조등은 운 전자에게 심리적으로 편안한 상태를 제공하는 것으로 판단 할 수 있었다(Derlofske et al., 2003). 기존 전조등과 비교 하여 심리적으로 편안한 상태인 운전자는 상대적으로 낮은 휘도일지라도 표지판을 더욱 쉽게 식별할 수 있는 것으로 예 측할 수 있었다.

\section{Conclusion}

본 연구는 전조등 종루와, 표지판 색상에 따른 식별거리를 정량적으로 분석하기 위해 수행하였다.

전조등의 식별거리 실험결과, 표지판의 색상 (백색 > 청색 $>$ 검은색)과 전조등의 종류(HID > LED > Halogen)에 따 라 차이가 발생하고 있었다. 그리고 식별거리에 따른 휘도 측정결과 색온도가 높을수록 낮은 휘도에서 표지판을 식별 하는 것으로 분석되었다.

기술발전에 따라 전조등의 성능과 기능은 발전하고 있다. 
특히 도로환경조건에 따라 전조등의 빛특성이 자동으로 변 동되는 시스템은 자동차가 정지된 상태에서 정확한 실험이 어렵기 때문에 주행상태에서 전조등의 식별거리를 제시할 수 있는 방법에 대한 추후 연구가 필요하다.

\section{References}

Blanco, M., et al. Enhanced Night Visibility Series: Phase II-Study 1: Visual Performance During Nighttime Driving in Clear Weather, FHWA-HRT-04-134, 9, 2005.

Bullough, J. D., Assessing Safety Outcomes Related to Driver Visibility and Behavior, Vision Symposium. 2010.

Chen, W., et al. A Study on Peripherral Visibility under Different Headlamp Low-beam Pattern, Journal of Light and Visual Environment., 82(4), 358-365, 2008.

Derlofske, J, V., Dyer, D. and Bullough, J. D., Visual Benefits of Blue Coated Lamps for Automotive Forward Lighting, SAE-2003-01-0930, 2003.

Ekrias, A., et al. Effects of Vehicle Headlights on Target Contrast in Road Lighting Environments, Journal of Light and Visual Environment, 32(3), 302-314, 2008.

Hung, C. C., et al. Optical Design of Automotive Headlight System incorporating Digital Micromirror Device, Applied optics, 49(22), 4182-4187, 2010.

Korea insurance development institute, Increase rate of accident for female drivers. http://www.kidi.kr(16/05/2011).

Micheal, F. T., Enhanced Night Visibility Series: Phase II Characterization of Experimental Objects, FHA, 9, 2005.

Schiller, C. and Khanh, T. Q., Photometrical and Physiological Aspects of Today's LED Car Headlamps, SAE-2008-2-15, 2008.

Tetsuaki Inaba, et al. LED Headlamp Development for Mass Production, SAE-2008-1-339, 2008.

Völker, S., New Headlamps - More Safety or Only More Glare?, Proceeding of 6th International Symposium on ISAL, 2005.

Wood, J. M., et al. Pedestrian Visibility at Night: Effects of Pedestrian Clothing, Driver Age, and Headlamp Beam Setting, Transportation Research Board, 2003.

Wördenweber, B., et al. Automotive Lighting and Human Vision, Springer, p.96, 2006.

\section{Author listings}

Jung-Yong Kim: jungkim@hanyang.ac.kr

Highest degree: $\mathrm{PhD}$, Department of Industrial Engineering, the Ohio state University

Position title: Professor, Department of Industrial and Management Engineering, Hanyang University

Areas of interest: UX/UI, Biomechanics, Cognitive psychology, Human interface design

Ho Sang Lee: 1hsang@ts2020.kr

Highest degree: MS, Graduate School of Engineering, Hanyang University

Position title: Doctoral candidate, Department of Industrial and Management Engineering, Hanyang University

Areas of interest: Headlamp, Behavioral Sciences, Human error, UX/UI, Biomechanics

Seung-Nam Min: dukorea@hanyang.ac.kr

Highest degree: MS, Department of Industrial Engineering, Hanyang University

Position title: Doctoral candidate, Department of Industrial and Management Engineering, Hanyang University

Areas of interest: Safety, Human Error, UX/UI, WMSD, Human interface design

Min Ho Lee: 1mh2075@nate.com

Highest degree: MS, Department of Industrial and Management Engineering, Hanyang University

Position title: Master degree, Department of Industrial and Management Engineering, Hanyang University

Areas of interest: Ergonomics, Cognitive Psychology, UI/UX, HCI,

Usability Test

Date Received : 2011-06-30

Date Revised :2012-03-22

Date Accepted : 2012-03-27 